Review

\title{
Molecular Interactions between NR4A Orphan Nuclear Receptors and NF-кB Are Required for Appropriate Inflammatory Responses and Immune Cell Homeostasis
}

\section{Evelyn P. Murphy and Daniel Crean *}

UCD Veterinary Sciences Centre, Conway Insitute for Biomolecular and Biomedical Research, University College Dublin, Dublin 4, Ireland; E-Mail: evelyn.murphy@ucd.ie

* Author to whom correspondence should be addressed; E-Mail: daniel.crean@ucd.ie; Tel.: +353-1-716-6215.

Academic Editor: Ivana Vancurova

Received: 30 April 2015 / Accepted: 16 June 2015 / Published: 29 June 2015

\begin{abstract}
Appropriate innate and adaptive immune responses are essential for protection and resolution against chemical, physical or biological insults. Immune cell polarization is fundamental in orchestrating distinct phases of inflammation, specifically acute phase responses followed by resolution and tissue repair. Dysregulation of immune cell and inflammatory responses is a hallmark of multiple diseases encompassing atherosclerosis, rheumatoid arthritis, psoriasis and metabolic syndromes. A master transcriptional mediator of diverse inflammatory signaling and immune cell function is NF- $\mathrm{kB}$, and altered control of this key regulator can lead to an effective switch from acute to chronic inflammatory responses. Members of the nuclear receptor (NR) superfamily of ligand-dependent transcription factors crosstalk with NF- $\kappa B$ to regulate immune cell function(s). Within the NR superfamily the NR4A1-3 orphan receptors have emerged as important regulators of immune cell polarization and NF- $\kappa \mathrm{B}$ signaling. NR4A receptors modulate NF- $\kappa \mathrm{B}$ activity in a dynamic fashion, either repressing or enhancing target gene expression leading to altered inflammatory outcome. Here we will discuss the pivotal role NR4A's receptors play in orchestrating

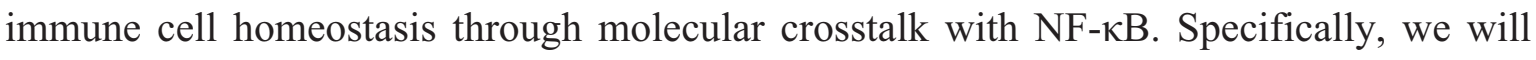
examine such NR4A/NF- $\mathrm{B}$ interactions within the context of distinct cell phenotypes, including monocyte, macrophage, $\mathrm{T}$ cells, endothelial, and mesenchymal cells, which play a role in inflammation-associated disease. Finally, we review the therapeutic potential of altering NR4A/NF- $\mathrm{kB}$ interactions to limit hyper-inflammatory responses in vivo.
\end{abstract}


Keywords: nuclear receptors; NR4A subfamily; NF-кB; inflammation; immune homeostasis

\section{Introduction: Appropriate Inflammation and NF-кB Activity}

Appropriate inflammatory responses to foreign pathogens or tissue injury are orchestrated by multiple cells types, including both resident (mast, endothelial, macrophage) and infiltrating (neutrophils, monocytes, macrophages, fibrocytes and T-cells) immune cells [1,2]. Innate immune sensors present on resident and infiltrating cells act to detect, initiate and propagate an inflammatory response $[3,4]$. These sensors are collectively known as pathogen recognition receptors (PRRs) and are activated by infectious agents such as foreign DNA, RNA, carbohydrates and non-infectious agents as occurs in "sterile" inflammatory processes [4,5]. Classes of PRRs include membrane bound sensors such as Toll-like receptors (TLRs), C-type lectins and cytoplasmic proteins such as NOD-like receptors (NLRs) and RIG-1-like receptors (RLRs) [3]. The major signaling pathways underlying PRR responses include mitogen activated protein kinases (MAPKs), IFN regulatory factors (IRFs) and NF- $\mathrm{B}[3,6]$.

Subsequent to PRR activation resident cells secrete a range of mediators including histamine, bradykinin, prostaglandin (PGs), leukotrienes (LTs), cytokines and chemokines which co-operate to alter vascular permeability and promote immune cell recruitment and extravasation $[7,8]$. Polymorphonuclear (PMN) cell extravasation, driven primarily by leukotriene (LTB4), is the first line of defence of the innate immune system leading to phagocytosis and destruction of harmful materials [9]. Monocytes and monocyte-derived macrophages represent another critical immune cell, involved in both direct functional responses, such as phagocytosis, and eliciting dynamic downstream effects by secreting cytokines and chemokines which are important for regulating multiple stages of an appropriate inflammatory response [10]. A phrase coined "lipid class switching" takes place at this juncture, whereby lipid mediators responsible for the resolution of inflammation are secreted by cells within the inflammatory exudate [7]. These lipid mediators include lipoxins (LXs), resolvins (E and D series) (Rvs), protectins (Prot) and maresins (Mar) [7]. Collectively these resolving mediators inhibit PMN infiltration and extravasation, attenuate pro-inflammatory cytokine production, normalize chemokine gradients and promote PMN-CCR5 expression and subsequent non-phlogistic macrophage phagocytosis of apoptotic/CCR5 expressing PMNs [7,11]. Meanwhile tissue macrophages, regulatory T cells (Tregs), myofibroblast and fibrocyte cells promote tissue repair and remodelling as a result of growth factors such as TGF- $\beta$ and ultimately tissue homeostasis $[11,12]$.

Central to the control of all phases of the inflammatory response is the transcription factor NF- $\kappa \mathrm{B}$, and aberrant regulation of NF-kB signaling has been associated with pathologies characterised by altered immune responses and chronic inflammation (reviewed in [6]). Importantly NF- $\kappa$ B activity can also direct several anti-inflammatory processes such as appropriate leukocyte apoptosis and TGF- $\beta$ release during the resolution phases of inflammation $[13,14]$. More than 25 years since the discovery of NF- $\kappa B$, extensive studies provide a multifaceted understanding of the cell- and tissue-specific activation and downstream responses controlled by NF-кB [6]. However, as recently reviewed by Hayden and Gosh, and primarily due to the complexities of NF- $\mathrm{\kappa B}$ activation and function, questions regarding molecular interactions at distinct levels of the NF- $\mathrm{NB}$ signaling pathway remain to be explored [6]. Over the past 
decade several members of the nuclear receptor superfamily (NR) have been uncovered as significant ligand-inducible proteins capable of influencing $\mathrm{NF}-\mathrm{\kappa B}$ activity in several cell types, including monocyte/macrophage cells. In this review article we discuss the role nuclear receptors play in mediating NF- $\kappa B$ regulation with a primary focus on the molecular interactions and crosstalk with the orphan nuclear receptor NR4A subfamily.

\section{Nuclear Receptor (NR) Modulation of NF-кB Signaling}

$\mathrm{NF}-\kappa \mathrm{B}$ is a master regulator downstream of TLR and TNF $\alpha$ signaling pathways $[15,16]$, and hence the molecular mechanisms by which NR's impact on this pathway, and discussed herein, are primarily undertaken using TLR4 and TNF $\alpha$-receptor (TNFR) stimulation (Figure 1). While in an inactivated state, NF- $\kappa B$ (p65/p50 heterodimer as depicted in Figure 1) is located in the cytoplasm bound with the inhibitory protein I $\mathrm{IB} \alpha$. Several extracellular signals including TNF $\alpha$ and LPS bind to integral membrane receptors (TNFR and TLR4) leading to activation of I $\kappa$ B kinase (IKK) which, in turn, phosphorylates the I $\kappa \mathrm{B} \alpha$ protein leading to ubiquitination and dissociation from the NF- $\kappa \mathrm{B}$ complex. The activated NF- $\kappa \mathrm{B}$ proteins translocate to the nucleus, recruit co-activators and subsequent binding to promoter regions to regulate target gene expression (Figure 1). Modulation of the NF- $\kappa \mathrm{B}$ pathway by members of the NR superfamily occurs both upstream, within cytoplasmic signaling components, and in the nucleus during NF- $\mathrm{B}$ DNA binding/transcriptional events (Figure 1). Given the central role of NRs in controlling NF- $\kappa$ B activity, the depletion or deletion of individual NRs can render myeloid cells to a hyper-NF- $\kappa \mathrm{B}$ activated/pro-inflammatory state (Figure 1).

Glucocorticoids are potent anti-inflammatory agents and owe the majority of their anti-inflammatory functions to NF- $\mathrm{B}$ inhibition [17]. The inhibitory effects of ligand activated glucocorticoid receptors (GR) on the NF- $\kappa B$ pathway occurs through the promotion of $\mathrm{I} \kappa \mathrm{B} \alpha$ protein expression and subsequent $\mathrm{NF}-\kappa \mathrm{B} / \mathrm{p} 65$ sequesterisation to the cytoplasm during TNF $\alpha$ exposure [18], a molecular mechanism also observed during TLR stimulation [19]. GR activation has also been shown to induce several anti-inflammatory factors known to inhibit NF- $\kappa$ B function in primary human PBMCs and immortalized macrophage cells, including IL-10 and glucocorticoid-induced leucine zipper (GILZ) [18-22]. Interestingly GILZ, induced by GR and IL-10 in macrophage cells, associates with NF- $\mathrm{kB} / \mathrm{p} 65$ and prevents transcription from NF- $\mathrm{BB}$-dependent regulatory elements [22]. Other mechanisms of GR inhibition of NF- $\kappa \mathrm{B}$ activity include more rapid removal of $\mathrm{NF}-\kappa \mathrm{B} / \mathrm{p} 65$ from the nucleus and inhibition of co-activating binding partners such as IRF3 [18,23].

Liver X receptor (LXR), a nuclear receptor involved chiefly in cholesterol homeostasis, has also been shown to impact on the NF- $\mathrm{B}$ pathway [24-27]. Castrillo et al. demonstrate LPS-induced matrix metalloproteinase-9 (MMP-9) is inhibited by LXR in macrophage cells [27]. Interestingly, the study identifies a $\kappa \mathrm{B}$ site on the MMP-9 promoter is essential for LXR inhibition, however, LXR does not alter I $\kappa \mathrm{B} \alpha$ expression or NF- $\kappa \mathrm{B} / \mathrm{p} 65$ DNA binding capacity. LXR activation in LPS stimulated macrophage cells inhibits the clearance of the NCoR/SMRT corepressor complex, thereby inhibiting NF- $\mathrm{BB}$ transcriptional activity [25]. This NCoR/SMRT co-repressor interaction was also identified as a primary mechanism for peroxisome proliferator-activated receptor gamma (PPAR $\gamma$ ) inhibition of NF- $\kappa$ B activity (Figure 1) [25]. In dendritic cells (DCs) LXR appears to have the opposite effect on NF- $\kappa \mathrm{B}$ activity and, during LPS exposure, positively increases activity leading to subsequent changes in target gene 
expression [28]. The mechanism in LPS-treated DCs was shown to be, in part, due to sustained IkB $\alpha$ phosphorylation by LXR and subsequent increase in NF- $\kappa B$ activation. Such differential responses highlight that specific cell types influence the molecular control of NF- $\kappa$ B activity by members of the NR family.

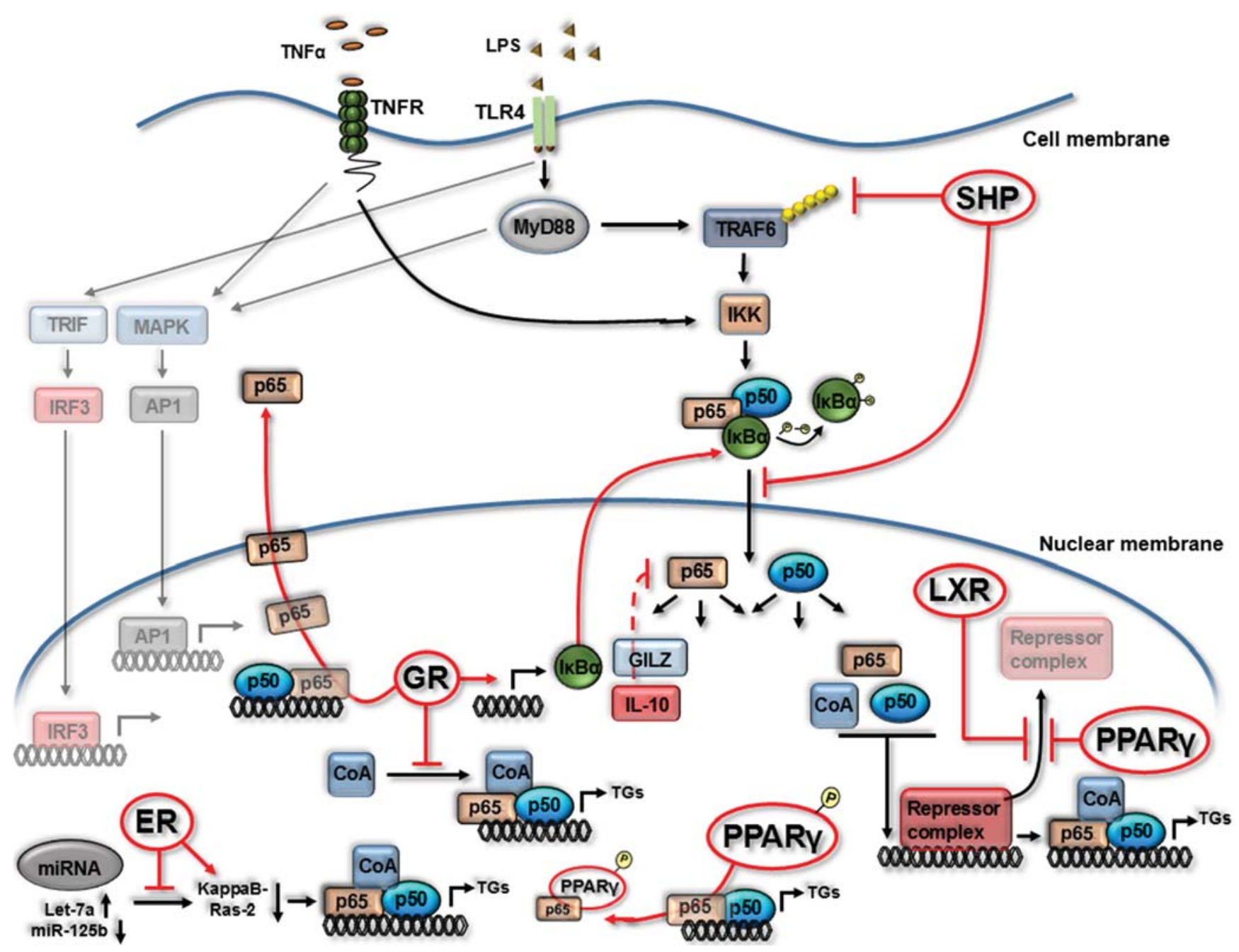

Figure 1. Nuclear receptors can alter NF- $\mathrm{kB}$ signaling and activity. Summary diagram depicting mechanisms by which nuclear receptors (NRs) impact the NF- $\mathrm{KB}$ signaling pathway downstream of TNF Receptor (TNFR) or Toll Like Receptor 4 (TLR4) as outlined within Section 2. Estrogen Receptor (ER), Glucocorticoid Receptor (GR), Peroxisome Proliferator-Activated Receptor gamma (PPAR $\gamma$ ), Liver X Receptor (LXR), small heterodimer partner (SHP), transcriptional co-activators (CoA), phosphorylation (P), target genes (TGs). Red arrows display NR interactions with NF- $\kappa B$ (both inhibitory indicated by a $\mathrm{T}$ bar and stimulatory indicated by an arrow head $\rightarrow$ ). Dashed arrow indicates multiple process involved.

Thus the mechanisms by which NRs inhibit NF-אB activity are diverse, and on-going and future studies will uncover even greater levels of molecular complexity. Recently, using murine macrophages, the orphan nuclear receptor small heterodimer partner (SHP) has been shown to inhibit NF- $\kappa \mathrm{B}$ activity at multiple stages of its pathway [29]. SHP can physically interact with NF- $\kappa \mathrm{B} / \mathrm{p} 65$, inhibiting its nuclear translocation, and can further modulate cytoplasmic TRAF6 ubiquitination/degradation, an important 
event as TRAF6 activates IKK in response to TLR4 activation (Figure 1). Furthermore, activation of estrogen receptor (ER) inhibits $\mathrm{NF}-\kappa \mathrm{B}$ activity in primary macrophages through alterations in miRNA-125b and Let-7a leading to the induction of kappaB-Ras2, an inhibitor of NF- $\kappa$ B signaling [30].

\section{NR4A Nuclear Receptors and NF-кB Signaling}

Emerging as significant regulators of inflammatory processes and immune homeostasis are the orphan nuclear receptor family 4A (NR4A). This subfamily is comprised of three members, NR4A1 (Nur77), NR4A2 (Nurr1) and NR4A3 (Nor-1) [2,31,32]. All three NR4A receptors are immediate early genes and expressed at high levels in a number of chronically inflamed human tissues and relevant mouse models, including atherosclerosis, arthritis, colitis and psoriasis [31-33]. To date no endogenous ligands have been described in the regulation of NR4A receptor activity, however pharmacological modulation of NR4A activity can be achieved with agents such as the anti-neoplastic agent, 6-mercaptopurine and a series of 1,1-bis(3-indolyl)-1-( $p$-substituted phenyl) methanes (C-DIMs) [34-36]. The NR4A1-3 receptors are constitutively active and their activity is controlled through transcriptional regulation, post translational modifications, protein interactions and subcellular localisation [31,32]. NF- $\kappa \mathrm{B}$ is a pivotal regulator of NR4A1,2,3 gene expression in myeloid-derived cell types and multiple studies reveal a regulatory feedback role for NR4A's in controlling NF- $\kappa B$ activity and pro-inflammatory target gene expression [37-41]. This regulation is primarily through repression of NF- $\kappa \mathrm{B}$ transcriptional activity, as discussed herein.

NR4A1 deficiency highlights how crucial this receptor is for the development of Ly6 $\mathrm{C}^{\text {low }}$ monocytes, particularly as Ly6C $\mathrm{C}^{\text {low }}$ monocytes are involved in inflammatory resolution [39]. The impact of loss of Ly6 $\mathrm{C}^{\text {low }}$ monocytes in NR4A $1^{-/}$mice leads to enhancement of atherosclerosis in two distinct models of disease $\left(\mathrm{Ldlr}^{-/-}\right.$and $\mathrm{ApoE} \mathrm{E}^{-/-}$) [40]. The study further reveals that NR4A1 functions to regulate macrophage phenotypes in vivo, with concomitant increases in TLR expression and enhanced NF- $\kappa \mathrm{B}-$ mediated target gene expression during TRL4 stimulation. Increased expression of IL-12, iNOS and enhanced responses to TLR agonists indicate polarisation of macrophages to an M1 pro-inflammatory phenotype. Using the selective and irreversible NF- $\kappa \mathrm{B}$ inhibitor, BAY 11-7082, genes altered in NR4A1-deficient macrophages were confirmed to be NF- $\mathrm{B}$ regulated targets. Furthermore, increased phosphorylation of $\mathrm{NF}-\kappa \mathrm{B} / \mathrm{p} 65$ was measured in these cells affirming that NR4A1 deficiency can lead to increased NF- $\kappa \mathrm{B}$-dependent inflammatory activation in macrophage cells [40]. Recently NR4A1-dependent Ly6 $\mathrm{C}^{\text {low }}$ monocytes have demonstrated a pivotal role in mediating intravascular homeostasis, in part by regulating necrosis of endothelial cells by neutrophils and subsequent phagocytic clearance [42].

Bone marrow specific deficiency of NR4A1 further reveals that bone marrow-derived macrophage (BMM) express higher levels of IL-12, IFN $\gamma$ and SDF-1 $\alpha$ with enhanced thioglycollate-elicited migration of macrophage and B cells. Again supporting a protective role for NR4A1 in hematopoietic cell in atherogenesis, transplantation of $\mathrm{NR} 4 \mathrm{~A} 1^{-/}$BMM to low density lipoprotein receptor-deficient $\left(\mathrm{Ldlr}^{--}\right)$mice enhances atherosclerosis with increased lesion size and enhanced macrophage and $\mathrm{T}$ cell numbers [41]. These observations support earlier studies by the de Vries group demonstrating how ectopic expression of NR4A1, 2 or 3 in human macrophage cells attenuates pro-inflammatory cytokine (IL-6, IL-1 $\beta$ and IL-8) and chemokine (MIP1 $\alpha$ and MCP-1) synthesis [38]. Additionally in similar human cells, knockdown of NR4A1 or NR4A3 expression results in enhanced TLR4-stimulated 
production of IL-1 $\beta$, IL-8 and MCP-1 [38]. Macrophage cell phenotype is not only characterised by cytokine/chemokine expression profile but rather a combination of secreted mediators and specific surface marker expression patterns. Interestingly NR4A1 ${ }^{-/}$macrophages isolated from atherosclerotic murine models display enhanced pro-inflammatory surface marker expression (MHC class II) and reduced anti-inflammatory marker expression (Arginase-1) [40].

The molecular mechanism by which NR4A receptors impact on NF- $\kappa \mathrm{B}$ activity came from the initial study of NR4A2 activity in microglia cells under TLR4 stimulation [43]. Depleted NR4A2 expression results in heightened pro-inflammatory responses in microglial cells. Within this cell model and following TLR4 stimulation, NR4A2 becomes SUMOylated (by protein inhibitor of activated STAT4) and phosphorylated (by nemo-like kinase) which in turn binds to phosphorylated NF- $\mathrm{B} / \mathrm{p} 65$ (by glycogen synthase kinase 3) on target gene promoter regions, leading to the recruitment of a repressor complex known as Co-REST [43]. Association of this repressor complex promotes clearance of NF- $\mathrm{BB} / \mathrm{p} 65$ from the promoter of targets genes such as $\mathrm{TNF} \alpha$ and subsequent dampening of pro-inflammatory responses [43] (Figure 2). NR4A2 recruitment to the promoter regions of pro-inflammatory gene targets, $\mathrm{TNF} \alpha$ and iNOS, was further confirmed using an in vivo model. Cell-specific knockdown of NR4A2 renders the cells to a hyper-inflammatory state with cellular responses further heightened following TLR4 stimulation, displaying augmented TNF $\alpha$, iNOS and IL1 $\beta$ production [43]. Altered expression of NR4A2 and -3 has been shown to guide macrophage polarization [44-46] with adoptive transfer experiments revealing that NR4A2 confers increased survival in endotoxin (LPS) induced sepsis [44]. Similar molecular mechanisms by NR4A1 are employed in controlling immune homeostasis in LPS-induced sepsis [47]. NR4A1 ${ }^{-/}$mice display an increased sensitivity to LPS-induced sepsis and death. In peritoneal macrophage cells NR4A1 functions to limit NF- $\mathrm{B}$ activity through the inhibition of $\mathrm{NF}-\kappa \mathrm{B} / \mathrm{p} 65$ binding to $\kappa \mathrm{B}$ binding sites on target gene promoters. Interestingly, the phosphorylation of NR4A1 by LPS-activated p38 $\alpha$ leads to loss of NR4A functional activity, suggesting that targeting the interaction of $\mathrm{p} 38 \alpha$ and NR4A1 would permit NR4A1 mediated control of hyper-inflammatory responses (Figure 2) [47].

Collectively these studies confirm that NR4A1-3 receptors are intimately involved in monocyte cell differentiation, with the loss of receptor activity promoting a hyper-inflammatory cell response. This NR4A-dependent pro-inflammatory activation state is mainly attributed to the loss of appropriate control

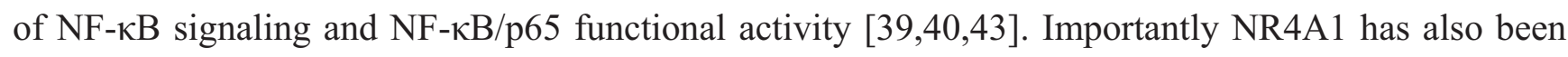
shown to promote NF- $\mathrm{KB}$ activity through the activation of IKKi in murine macrophage cells [48]. Additionally, within models of vascular injury, NR4A3/Nor-1 can protect or potentiate neointima formation following insult leading to diverse outcomes [49-53]. Such differences may underlie additional complexities to the function(s) of NR4A receptors, as a consequence of tissue environment, cell or stimuli specific effects. Hence to clarify the role of NR4A3 in mediating the response of vascular smooth muscle cells to inflammatory stimuli, in vivo cell specific gain and loss of function studies have recently been undertaken [50,51]. NR4A3 was shown to direct and limit the inflammatory response by inhibiting $\mathrm{NF}-\mathrm{kB} / \mathrm{p} 65$ activation, nuclear translocation and target gene expression [51]. 


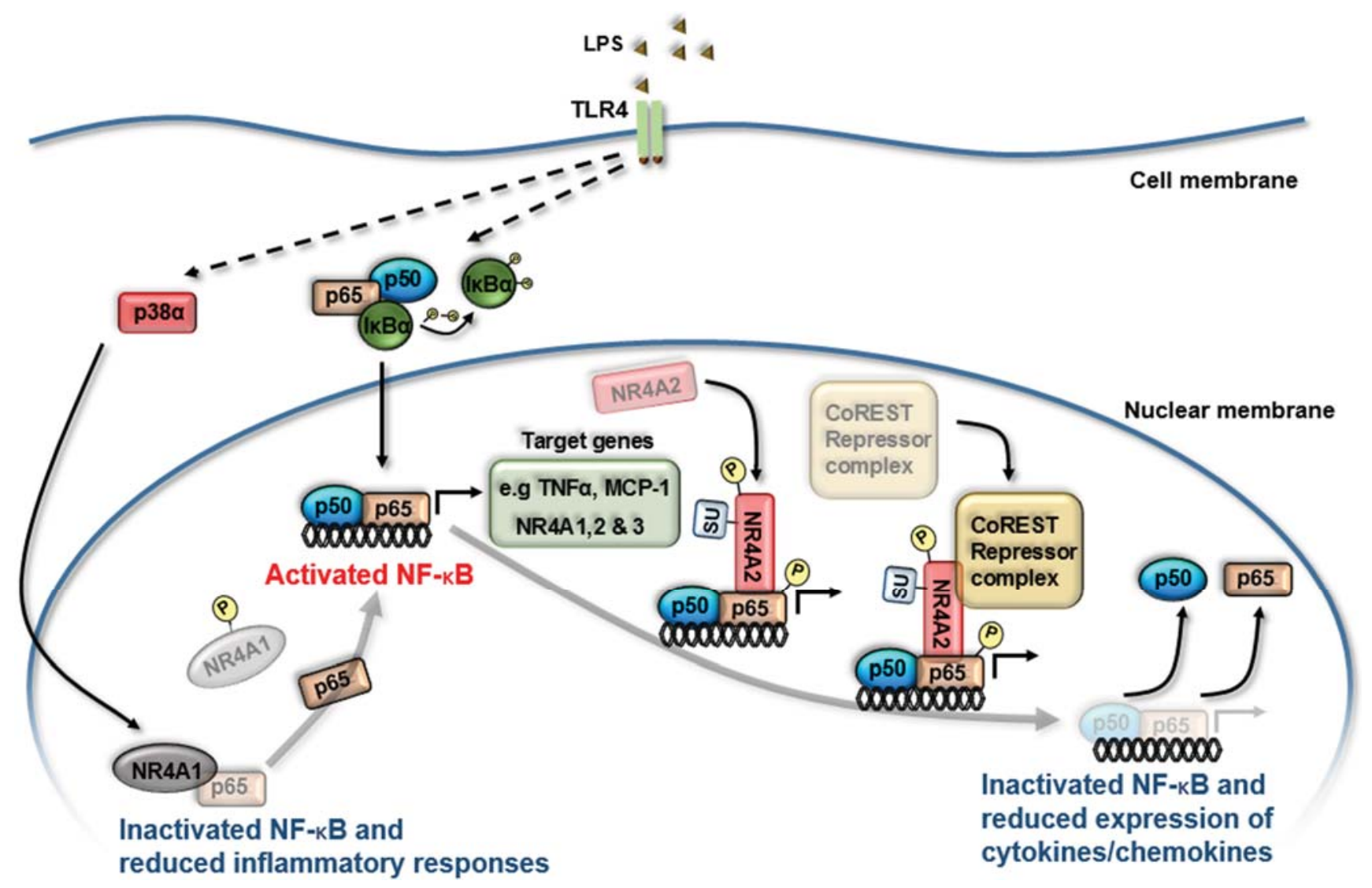

Figure 2. NR4A receptors regulate $\mathrm{NF}-\kappa \mathrm{B}$ activity to limit inflammatory responses. Summary diagram displaying the molecular mechanisms by which NR4A receptors regulate $\mathrm{NF}-\kappa \mathrm{B}$ transcriptional activity downstream of Toll Like Receptor 4 (TLR4) activation. LPS treatment of myeloid-derived cells triggers the transcriptional induction of all three NR4A receptors via NF- $\kappa B$ (p50/p65 heterodimer) binding to $\kappa B$ sites within their promoter regions. Enhanced NR4A1 and NR4A2 expression functions to limit the inflammatory response by altering NF- $\mathrm{kB}-$ dependent regulation of cytokine and chemokine gene expression. During inflammation NR4A2 becomes SUMOylated (by protein inhibitor of activated STAT4) and phosphorylated (by nemo-like kinase) which in turn binds to phosphorylated NF- $\mathrm{kB} / \mathrm{p} 65$ (by glycogen synthase kinase-3) on target gene promoter regions, leading to the recruitment of a repressor complex known as Co-REST. LPS/TLR-activated p38 $\alpha$ phosphorylates NR4A1 to reduce NR4A1-dependent suppression of a hyper-inflammatory response through NR4A1 inhibition of $\mathrm{NF}-\kappa \mathrm{B} / \mathrm{p} 65$ binding to $\kappa \mathrm{B}$ sites within promoter regions of target genes. SUMOylation (SU), phosphorylation (P).

\section{NR4A Control of Acute Inflammation, Inflammatory Resolution and Tissue Repair}

Target genes and physiological functions of NR4A receptors are cell type and context dependent. Therefore, and as summarised below, the study of distinct cell types in models of inflammation-associated disease is proving critical to uncovering NR4A receptor involvement in tissue responses that promote inflammatory resolution including acute inflammation, vascular permeability, angiogenesis and tissue remodelling. 


\subsection{NR4A1 is Crucial for the Development of Ly6C low Reparative Monocytes and Has an Anti-Inflammatory Effect in Monocyte/Macrophage Cells}

Treatment of monocyte/macrophage cells with LPS, cytokines, or oxidized lipids triggers the transcriptional induction of all three NR4A receptors [37,44]. Functional studies demonstrate both pro- and anti-inflammatory functions for NR4A receptors suggesting that the temporal expression levels and activity of these receptors in monocyte/macrophage cells may permit differential effects on gene expression and transcriptional outcomes. In models of acute myocardial infarction (MI), healing and tissue remodeling requires monocyte/macrophage cells which persist for days in the infarct zone and contribute to diverse functions including inflammation, proteolysis, phagocytosis, angiogenesis and collagen deposition [54,55]. It is proposed that heterogeneity of monocyte subtypes leads to biphasic cellular and molecular events that control these functions and influence healing and remodeling [56]. Recently a role for NR4A1 has been demonstrated within a murine model of acute MI. Mice lacking NR4A1 on hematopoietic cells, display increased inflammatory responses and compromised healing responses following acute MI. Enhanced accumulation of $\mathrm{NR} 4 \mathrm{~A} 1^{-1-}$ monocytes and macrophage cells are measured in myocardial infarct tissue. In the absence of NR4A1, Ly-6C ${ }^{\text {high }}$ monocytes express high levels of CCR2, infiltrate myocardium in excessive numbers and differentiate to abnormal inflammatory macrophages [56]. These studies indicate that NR4A1 activity is required to balance an early monocyte-dominant inflammatory response and a later macrophage-dominant reparative phase. Such observations enrich our mechanistic understanding of the diverse molecular events controlled by NR4A receptors within monocyte/macrophages which may have biological relevance beyond MI. Regarding the functional role of NF- $\mathrm{B}$ activity in MI, studies demonstrate NF- $\kappa \mathrm{B}$ activation during acute injury is protective whereas prolonged activation leads to tissue damage [57]. It is becoming more evident that the local environment influences the differentiation stage/function of immune cells, thus determining the cell specific contribution NR4A receptors play in guiding inflammatory responses and outcomes [56,57].

\subsection{Generation and Maintenance of Regulatory T Cells by NR4A Receptors}

In CD4/CD8 double-positive thymocytes and $\mathrm{T}$ cell hybridomas, NR4A expression is induced through the $\mathrm{T}$ cell receptor (TCR) and is implicated in activation-induced apoptosis during negative selection [58]. Overexpression of NR4A1 in the human T cell leukemia cell line (Jurkat) can repress expression of IL-2 via negative regulation of NF- $\mathrm{B}$ activity [59]. Mice lacking all three NR4A family members fail to produce regulatory $\mathrm{T}$ (Treg) cells and die prematurely due to uncontrolled systemic multi-organ inflammation resembling the phenotype of Forkhead transcription factor, Foxp3, deficient mice [60]. Ectopic expression of NR4A2 induces the expression of Foxp3, which through the suppression of effector cytokine production, plays a critical role in the differentiation, maintenance and effector functions of Treg cells [61]. Alternatively, chromatin immunoprecipitation of endogenous NR4A proteins reveals that each NR4A family member can bind the Foxp3 promoter in stimulated naive T cells. Thus, all three NR4A transcription factors are potentially able to activate Foxp3 expression to promote Treg development and functions [60]. Recent work by the Hedrick group has further established a key role for NR4A1 in regulating appropriate CD8 $+\mathrm{T}$ cell development through modulation of 
Runx3 [62]. The authors reveal during CD8+ T cell development NR4A1 recruits the co-repressor CoREST complex, binds to a distal promoter region of the Runx3 gene, and subsequent gene repression [62].

As highlighted in Figure 1, TRAF6 is a key upstream regulator of NF- $\kappa$ B signaling. TRAF6 has been shown to play an essential role in activating NF- $\kappa B$ in $\mathrm{T}$ cells, and recent studies indicate that this protein also plays a critical role in the development of Treg cells. TRAF6 deficiency leads to reduced expression and stability of Foxp3 and a rapid conversion of Foxp $3^{+}$Tregs to Foxp3 ${ }^{-}$cells [63]. Molecular interactions between NR4A/TRAF6/NF- $\mathrm{kB}$ in Foxp3 expression during Treg development and maintenance is unknown and remains to be studied.

\subsection{Role of NR4A Receptors in Maintaining Endothelial Cell Homeostasis}

Changes in endothelial cell (EC) activation, vascular permeability and angiogenesis are early histopathological events that facilitate leukocyte ingress into inflamed tissue. NR4A1 protects ECs from $\mathrm{TNF} \alpha$ - and IL1 $\beta$-induced endothelial activation. Attenuation is mediated through the induction of IкB $\alpha$ and subsequent inhibition of NF- $\mathrm{BB}$ activity and transcriptional regulation of adhesion molecule expression [64]. NR4A1 transcriptional activity has also been shown to regulate vascular permeability in vitro and in vivo by enhancing endothelial NO synthase and down-regulating several EC junction proteins that are required to maintain vascular homeostasis $[65,66]$.

The dynamic balance of positive and negative effectors of angiogenesis is of critical importance in the regulation of new vessel formation and stability in health and disease. NR4A1 transcriptional activity is both necessary and sufficient for VEGF-A-Induced proliferation and survival of cultured endothelial cells (ECs) and for angiogenesis in vivo, while depletion of NR4A2 expression attenuates VEGF-A-induced endothelial proliferation, migration and in vivo matrigel angiogenesis $[67,68]$. A role for NR4A receptors in regulating the expression of the endogenous angiogenesis inhibitor, thrombospondin-1 (TSP-1), has been recently explored. In human inflammatory arthritis the expression pattern of TSP-1 is significantly altered and these levels can be restored in patients responding to TNF $\alpha$ inhibition [69]. Further studies have uncovered an inverse relationship between NF- $\mathrm{kB}$ activity and TSP-1 expression in vivo and in vitro studies confirm NF- $\mathrm{BB}$-dependent repression of TSP-1 promoter activity, mRNA and protein expression [69]. NR4A2 functions as a transcriptional repressor of TSP-1 in human synovial tissue leading to reduced TSP-1 expression [69]. The identification of TSP-1 as a target of NR4A2 activity complements and enhances studies proposing a pro-angiogenic role for the NR4A subfamily of receptors in vivo. Interestingly, another member of this nuclear receptor family, PPAR, has been shown to modulate TSP-1 during early inflammation. PPAR $\alpha^{-/}$in leukocytes results in enhanced TSP-1 expression while PPAR $\gamma$ ligands greatly augment the pro-apoptotic effects of the TSP-1 derived peptide, ABT510 [70,71].

Physiologic angiogenesis plays an important role in tissue repair/wound healing and the involvement of endothelial NR4A1-3 receptor activity in skin wound healing is under review [72,73]. Initial studies indicate that $\mathrm{NR} 4 \mathrm{~A}^{-/-}$mice have comparable skin healing to wild-type littermates [73]. However the healing process is significantly delayed in in EC-NR4A1-dominant negative mice, in which a dominant negative NR4A1 mutant is inducible and specifically expressed in mouse ECs. Taken together these data suggest that NR4A1 and family members, NR4A2 and -3, play an effective and redundant role in normal skin would healing [73]. 


\subsection{NR4A Receptors Mediate Growth Factor and Cytokine Responses in Mesenchymal Cells}

The transdifferentiation of epithelial cells into motile mesenchymal cells (epithelial mesenchymal transition-EMT) is integral in development, stem cell behavior and wound healing, and contributes pathologically to fibrosis, inflammatory arthritis and cancer progression [74]. During EMT the reprogramming of gene expression are initiated and controlled by intracellular pathways that respond to extracellular mediators including pro-inflammatory cytokines and growth factors of which TGF- $\beta$ has a predominant role [74].

Migration and invasion of mesenchymal derived fibroblast-like synoviocytes (FLSs) are critical in the pathogenesis of rheumatoid arthritis (RA). Enhanced NR4A2 activity induces a phenotypic shift in normal FLS that parallels the cellular transformation and hyperplasia observed during the progression of inflammatory arthritis [75]. Through the generation of stable and transient NR4A2 expressing FLS, an in vitro cell system that reflects the characteristics of activated primary FLS was created. NR4A2 over-expressing cell lines express high VEGF-A and IL-8 levels, with significantly reduced TSP-1 mRNA and secreted_protein levels [69]. Further studies confirm that TNF $\alpha$ control of IL-8 expression and secretion by FLS is through a co-operative NR4A2/NF- $\kappa$ B driven process $[69,76]$. NF- $\kappa \mathrm{B}$ inhibition attenuates TNF $\alpha$-driven IL-6, IL-8 and MCP-1 in FLSs [77] and NF- $\kappa B$ inhibition is a protective therapeutic preventing the development of collagen induced arthritis (CIA) [77]. Such observations are supported by NR4A1 and NR4A2 gain of function experiments which reveal enhanced IL-6 and IL-8 production by bone marrow derived mesenchymal stromal cells [78]. In breast cancer NR4A1 activity is involved in mediating inflammation-induced epithelial to mesenchymal transition and breast metastasis [79]. Inflammatory mediators induce NR4A1 expression which drives TGF-B mediated breast cell migration, invasion and metastasis in vitro and in vivo. Notably, NR4A1 expression levels are elevated in breast cancer patients with high immune cell infiltration and levels correlate with poor prognosis [79]. Recent characterization of experimentally induced skin, lung, liver and kidney fibrosis in mice further identifies a regulatory role of NR4A1 in controlling aberrant TGF- $\beta$ signaling [72]. Thus, disease stage, sustained chronic inflammatory stimuli, including the balance of pro-inflammatory cytokines and TGF- $\beta$, may determine NR4A levels of activity which directs their functional role(s) in disease progression.

\section{Therapeutic Potential of Altering NR4A/NF-кB Interactions to Control Inflammation}

The ability of NR4A1-3 receptors to integrate and limit inflammatory signaling and promote tissue repair makes these receptors potential targets for therapeutic intervention. Endogenous ligands have yet to be identified for members of the NR4A subfamily. These receptors may be termed as "true" orphan receptors due to the presence of large hydrophobic side chains within their ligand binding domains (LBD) that may preclude ligand binding [32,34,36,80]. Modulating NR4A receptor activity has focused on altering expression levels, modulating cellular localization and impacting on interactions with co-regulatory proteins $[32,36]$. Pharmacological modulation of NR4A activity can be achieved with the anti-neoplastic agent, 6-mercaptopurine, and related compounds including adenosine [35,46]. A structurally different class of NR4A ligands include a series of 1,1-bis(3-indolyl)-1-( $p$-substituted phenyl) methanes (C-DIMs) which have been identified as potential NR4A1/2 agonists [34]. Recent studies reveal that in microglial cells [81], C-DIMs can increase NR4A2 nuclear localisation, stabilization of Co-REST and 
$\mathrm{NCoR} 2$ complexes and subsequent inhibition of $\mathrm{NF}-\mathrm{\kappa B} / \mathrm{p} 65$ signaling, supporting the earlier NR4A2/NF- $\mathrm{BB}$ study by Glass and colleagues [43]. The in vivo therapeutic potential of targeting NR4A/NF- $\kappa B$ interactions to control immune homeostasis has recently been uncovered (Figure 2) [47]. A chemical compound n-pentyl 2-[3,5-dihydroxy-2-(1-nonanoyl)-phenyl]acetate (PDNPA) is shown to target the LBD of NR4A1 and prevents phosphorylation of NR4A1 by TLR-activated p38 $\alpha$. Loss of NR4A1 phosphorylation restores and maintains NR4A1 suppression of a hyper-inflammatory response through NR4A1 inhibition of $\mathrm{NF}-\kappa \mathrm{B} / \mathrm{p} 65$ binding to $\kappa \mathrm{B}$ sites within promoter regions of target genes [47]. Thus, pharmacological modulation of NR4A receptors with therapeutic potential to control hyper-inflammatory responses is developing and extremely promising. However, as revealed through the study of distinct inflammatory-associated diseases, cell type, cell context and disease stage can influence NR4A receptor functions, and consequently effective therapeutic NR4A modulation to ensure appropriate inflammatory resolution and repair may be challenging.

\section{Conclusions}

NR4A1-3 orphan nuclear receptors have emerged as significant regulators of the inflammatory response modulating NF- $\mathrm{\kappa B}$ signaling and activity in distinct cell types including monocyte/macrophage cells. NR4A receptors are required in inflammatory disease initiation and progression, where they function as early response regulators, controlling the extent of the inflammatory response and promoting inflammatory resolution. Given the pivotal role myeloid cells play in chronic inflammatory diseases NR4A receptors are an attractive target for therapeutic intervention. However, cognizance of the observations that cell-type and cellular microenvironment can alter NR4A receptor activity and influence their biological roles, the study of appropriate in vivo models of inflammatory disease will be important to ascertain their applicability as therapeutic targets.

\section{Acknowledgments}

This work was supported by Science Foundation Ireland funding (IN.1B2613) to Evelyn P. Murphy.

\section{Author Contributions}

Both authors contributed equally to article conception, planning, preparation and revision.

\section{Conflicts of Interest}

The authors declare no conflict of interest.

\section{References}

1. Medzhitov, R. Origin and physiological roles of inflammation. Nature 2008, 454, 428-435.

2. Huang, W.; Glass, C.K. Nuclear receptors and inflammation control: Molecular mechanisms and pathophysiological relevance. Arterioscler. Thromb. Vasc. Biol. 2010, 30, 1542-1549.

3. Mogensen, T.H. Pathogen recognition and inflammatory signaling in innate immune defenses. Clin. Microbiol. Rev. 2009, 22, 240-273. 
4. Wu, J.; Chen, Z.J. Innate immune sensing and signaling of cytosolic nucleic acids. Annu. Rev. Immunol. 2014, 32, 461-488.

5. Chen, G.Y.; Nuñez, G. Sterile inflammation: Sensing and reacting to damage. Nat. Rev. Immunol. 2010, 10, 826-837.

6. Hayden, M.S.; Ghosh, S. NF- $\kappa \mathrm{B}$, the first quarter century: Remarkable progress and outstanding questions. Genes Dev. 2012, 26, 203-234.

7. Serhan, C.N. Pro-resolving lipid mediators are leads for resolution physiology. Nature 2014, 510, 92-101.

8. Ryan, A.; Godson, C. Lipoxins: Regulators of resolution. Curr. Opin. Pharmacol. 2010, 10, $166-172$.

9. Segal, A.W. How neutrophils kill microbes. Annu. Rev. Immunol. 2005, 23, 197-223.

10. Wynn, T.A.; Chawla, A.; Pollard, J.W. Macrophage biology in development, homeostasis and disease. Nature 2013, 496, 445-455.

11. Maderna, P.; Godson, C. Lipoxins: Resolutionary road. Br. J. Pharmacol. 2009, 158, 947-959.

12. Bellini, A.; Mattoli, S. The role of the fibrocyte, a bone marrow-derived mesenchymal progenitor, in reactive and reparative fibroses. Lab. Invest. 2007, 87, 858-870.

13. Lawrence, T.; Gilroy, D.W.; Colville-Nash, P.R.; Willoughby, D.A. Possible new role for NF-kappaB in the resolution of inflammation. Nat. Med. 2001, 7, 1291-1297.

14. Lawrence, T. The nuclear factor NF-kappaB pathway in inflammation. Cold Spring Harb. Perspect. Biol. 2009, doi:10.1101/cshperspect.a001651.

15. Kawai, T.; Akira, S. Signaling to NF-kappaB by Toll-like receptors. Trends Mol. Med. 2007, 13, 460-469.

16. Hayden, M.S.; Ghosh, S. Regulation of NF-kB by TNF family cytokines. Semin. Immunol. 2014, 26, 253-266.

17. D’Acquisto, F.; May, M.J.; Ghosh, S. Inhibition of nuclear factor kappa B (NF-B): An emerging theme in anti-inflammatory therapies. Mol. Interv. 2002, 2, 22-35.

18. Scheinman, R.I.; Cogswell, P.C.; Lofquist, A.K.; Baldwin, A.S., Jr. Role of transcriptional activation of I kappa B alpha in mediation of immunosuppression by glucocorticoids. Science 1995, 270, 283-286.

19. Crinelli, R.; Antonelli, A.; Bianchi, M.; Gentilini, L.; Scaramucci, S.; Magnani, M. Selective inhibition of NF- $\kappa \mathrm{B}$ activation and TNF-alpha production in macrophages by red blood cell-mediated delivery of dexamethasone. Blood Cells Mol. Dis. 2000, 26, 211-222.

20. Driessler, F.; Venstrom, K.; Sabat, R.; Asadullah, K.; Schottelius, A.J. Molecular mechanisms of interleukin-10-mediated inhibition of NF-kappaB activity: A role for p50. Clin. Exp. Immunol. 2004, 135, 64-73.

21. Wang, P.; Wu, P.; Siegel, M.I.; Egan, R.W.; Billah, M.M. Interleukin (IL)10 inhibits nuclear factor kappa B (NF kappa B) activation in human monocytes. IL-10 and IL-4suppress cytokine synthesis by different mechanisms. J. Biol. Chem. 1995, 270, 9558-9563.

22. Berrebi, D.; Bruscoli, S.; Cohen, N.; Foussat, A.; Migliorati, G.; Bouchet-Delbos, L.; Maillot, M.C.; Portier, A.; Couderc, J.; Galanaud, P.; et al. Synthesis of glucocorticoid-induced leucine zipper (GILZ) by macrophages: An anti-inflammatory and immunosuppressive mechanism shared by glucocorticoids and IL-10. Blood 2003, 101, 729-738. 
23. Nelson, G.; Wilde, G.J.; Spiller, D.G.; Kennedy, S.M.; Ray, D.W.; Sullivan, E.; Unitt, J.F.; White, M.R. NF-kappaB signalling is inhibited by glucocorticoid receptor and STAT6 via distinct mechanisms. J. Cell Sci. 2003, 116, 2495-2503.

24. Calkin, A.C.; Tontonoz, P. Liver $\mathrm{X}$ receptor signaling pathways and atherosclerosis. Arterioscler. Thromb. Vasc. Biol. 2010, 30, 1513-1518.

25. Ghisletti, S.; Huang, W.; Jepsen, K.; Benner, C.; Hardiman, G.; Rosenfeld, M.G.; Glass, C.K. Cooperative NCoR/SMRT interactions establish a corepressor-based strategy for integration of inflammatory and anti-inflammatory signaling pathways. Genes Dev. 2009, 23, 681-693.

26. Terasaka, N.; Hiroshima, A.; Ariga, A.; Honzumi, S.; Koieyama, T.; Inaba, T.; Fujiwara, T. Liver $\mathrm{X}$ receptor agonists inhibit tissue factor expression in macrophages. FEBS J. 2005, 272, 1546-1556.

27. Castrillo, A.; Joseph, S.B.; Marathe, C.; Mangelsdorf, D.J.; Tontonoz, P. Liver X receptor-dependent repression of matrix metalloproteinase-9 expression in macrophages. J. Biol. Chem. 2003, 278, 10443-10449.

28. Töröcsik, D.; Baráth, M.; Benko, S.; Széles, L.; Dezso, B.; Póliska, S.; Hegyi, Z.; Homolya, L.; Szatmári, I.; Lányi, A.; et al. Activation of liver X receptor sensitizes human dendritic cells to inflammatory stimuli. J. Immunol. 2010, 184, 5456-5465.

29. Yuk, J.M.; Shin, D.M.; Lee, H.M.; Kim, J.J.; Kim, S.W.; Jin, H.S.; Yang, C.S.; Park, K.A.; Chanda, D.; Kim, D.K.; et al. The orphan nuclear receptor SHP acts as a negative regulator in inflammatory signaling triggered by Toll-like receptors. Nat. Immunol. 2011, 12, 742-751.

30. Murphy, A.J.; Guyre, P.M.; Pioli, P.A. Estradiol suppresses NF-kappa B activation through coordinated regulation of let-7a and miR-125b in primary human macrophages. J. Immunol. 2010, 184, 5029-5037.

31. Zhao, Y.; Bruemmer, D. NR4A orphan nuclear receptors: Transcriptional regulators of gene expression in metabolism and vascular biology. Arterioscler. Thromb. Vasc. Biol. 2010, 30, 1535-1541.

32. McMorrow, J.P.; Murphy, E.P. Inflammation: A role for NR4A orphan nuclear receptors? Biochem. Soc. Trans. 2011, 39, 688-693.

33. Qing, H.; Liu, Y.; Zhao, Y.; Aono, J.; Jones, K.L.; Heywood, E.B.; Howatt, D.; Binkley, C.M.; Daugherty, A.; Liang, Y.; et al. Deficiency of the NR4A orphan nuclear receptor NOR1 in hematopoietic stem cells accelerates atherosclerosis. Stem Cells 2014, 32, 2419-2429.

34. Safe, S.; Jin, U.H.; Hedrick, E.; Reeder, A.; Lee, S.O. Minireview: Role of orphan nuclear receptors in cancer and potential as drug targets. Mol. Endocrinol. 2014, 28, 157-172.

35. Pearen, M.A.; Muscat, G.E. Minireview: Nuclear hormone receptor 4A signaling: Implications for metabolic disease. Mol. Endocrinol. 2010, 24, 1891-1903.

36. Mohan, H.M.; Aherne, C.M.; Rogers, A.C.; Baird, A.W.; Winter, D.C.; Murphy, E.P. Molecular pathways: The role of NR4A orphan nuclear receptors in cancer. Clin. Cancer Res. 2012, 18, 3223-3228.

37. Pei, L.; Castrillo, A.; Chen, M.; Hoffmann, A.; Tontonoz, P. Induction of NR4A orphan nuclear receptor expression in macrophages in response to inflammatory stimuli. J. Biol. Chem. 2005, 280, $29256-29262$. 
38. Bonta, P.I.; van Tiel, C.M.; Vos, M.; Pols, T.W.; van Thienen, J.V.; Ferreira, V.; Arkenbout, E.K.; Seppen, J.; Spek, C.A.; van der Poll, T.; et al. Nuclear receptors Nur77, Nurr1, and NOR-1 expressed in atherosclerotic lesion macrophages reduce lipid loading and inflammatory responses. Arterioscler. Thromb. Vasc. Biol. 2006, 26, 2288-2294.

39. Hanna, R.N.; Carlin, L.M.; Hubbeling, H.G.; Nackiewicz, D.; Green, A.M.; Punt, J.A.; Geissmann, F.; Hedrick, C.C. The transcriptional factor NR4A1 controls bone marrow differentiation and the survival of Ly6C-monocytes. Nat. Immunol. 2011, 12, 778-785.

40. Hanna, R.N.; Shaked, I.; Hubbeling, H.G.; Punt, J.A.; Wu, R.; Herrley, E.; Zaugg, C.; Pei, H.; Geissmann, F.; Ley, K.; et al. NR4A1 (Nur77) deletion polarizes macrophages toward an inflammatory phenotype and increases atherosclerosis. Circ. Res. 2012, 110, 416-427.

41. Hamers, A.A.; Vos, M.; Rassam, F.; Marinković, G.; Kurakula, K.; van Gorp, P.J.; de Winther, M.P.; Gijbels, M.J.; de Waard, V.; de Vries, C.J. Bone marrow-specific deficiency of nuclear receptor Nur77 enhances atherosclerosis. Circ. Res. 2012, 110, 428-438.

42. Carlin, L.M.; Stamatiades, E.G.; Auffray, C.; Hanna, R.N.; Glover, L.; Vizcay-Barrena, G.; Hedrick, C.C.; Cook, H.T.; Diebold, S.; Geissmann, F. Nr4a1-dependent Ly6C ${ }^{\text {low }}$ monocytes monitor endothelial cells and orchestrate their disposal. Cell 2013, 153, 362-375.

43. Saijo, K.; Winner, B.; Carson, C.T.; Collier, J.G.; Boyer, L.; Rosenfeld, M.G.; Gage, F.H.; Glass, C.K. A Nurr1/CoREST pathway in microglia and astrocytes protects dopaminergic neurons from inflammation-induced death. Cell 2009, 137, 47-59.

44. Mahajan, S.; Saini, A.; Chandra, V.; Nanduri, R.; Kalra, R.; Bhagyaraj, E.; Khatri, N.; Gupta, P. Nuclear receptor $\mathrm{Nr} 4 \mathrm{a} 2$ promotes alternative polarization of macrophages and confer protection in sepsis. J. Biol. Chem. 2015, doi:10.1074/jbc.M115.638064.

45. De Paoli, F.; Eeckhoute, J.; Copin, C.; Vanhoutte, J.; Duhem, C.; Derudas, B.; Dubois-Chevalier, J.; Colin, S.; Zawadzki, C.; Jude, B.; et al. The neuron-derived orphan receptor 1 (NOR1) is induced upon human alternative macrophage polarization and stimulates the expression of markers of the M2 phenotype. Atherosclerosis 2015, 241, 18-26.

46. Crean, D.; Cummins, E.P.; Bahar, B.; Mohan, H.M.; McMorrow, J.P.; Murphy, E.P. Adenosine modulates NR4A orphan nuclear receptors to attenuate hyper-inflammatory responses in monocytic cells. J. Immunol. 2015, in press.

47. Li, L.; Liu, Y.; Chen, H.Z.; Li, F.W.; Wu, J.F.; Zhang, H.K.; He, J.P.; Xing, Y.Z.; Chen, Y.; Wang, W.J.; et al. Impeding the interaction between Nur77 and p38 reduces LPS-induced inflammation. Nat. Chem. Biol. 2015, 11, 339-346.

48. Pei, L.; Castrillo, A.; Tontonoz, P. Regulation of macrophage inflammatory gene expression by the orphan nuclear receptor Nur77. Mol. Endocrinol. 2006, 20, 786-794.

49. Arkenbout, E.K.; de Waard, V.; van Bragt, M.; van Achterberg, T.A.; Grimbergen, J.M.; Pichon, B.; Pannekoek, H.; de Vries, C.J. Protective function of transcription factor TR3 orphan receptor in atherogenesis: Decreased lesion formation in carotid artery ligation model in TR3 transgenic mice. Circulation 2002, 106, 1530-1535.

50. Rodríguez-Calvo, R.; Guadall, A.; Calvayrac, O.; Navarro, M.A.; Alonso, J.; Ferrán, B.; de Diego, A.; Muniesa, P.; Osada, J.; Rodríguez, C.; et al. Over-expression of neuron-derived orphan receptor-1 (NOR-1) exacerbates neointimal hyperplasia after vascular injury. Hum. Mol. Genet. 2013, 22, 1949-1959. 
51. Calvayrac, O.; Rodríguez-Calvo, R.; Martí-Pamies, I.; Alonso, J.; Ferrán, B.; Aguiló, S.; Crespo, J.; Rodríguez-Sinovas, A.; Rodríguez, C.; Martínez-González, J. NOR-1 modulates the inflammatory response of vascular smooth muscle cells by preventing NFkB activation. J. Mol. Cell. Cardiol. 2015, 80, 34-44.

52. Rodríguez-Calvo, R.; Ferrán, B.; Alonso, J.; Martí-Pàmies, I.; Aguiló, S.; Calvayrac, O.; Rodríguez, C.; Martínez-González, J. NR4A receptors up-regulate the antiproteinase alpha-2 macroglobulin (A2M) and modulate MMP-2 and MMP-9 in vascular smooth muscle cells. Thromb. Haemost. 2015, 113, $1323-1324$.

53. Nomiyama, T.; Zhao, Y.; Gizard, F.; Findeisen, H.M.; Heywood, E.B.; Jones, K.L.; Conneely, O.M.; Bruemmer, D. Deficiency of the NR4A neuron-derived orphan receptor-1 attenuates neointima formation after vascular injury. Circulation 2009, 119, 577-586.

54. Weinberger, T.; Schulz, C. Myocardial infarction: A critical role of macrophages in cardiac remodeling. Front. Physiol. 2015, doi:10.3389/fphys.2015.00107.

55. Ren, G.; Dewald, O.; Frangogiannis, N.G. Inflammatory mechanisms in myocardial infarction. Curr. Drug Targets Inflamm. Allergy 2003, 2, 242-256.

56. Hilgendorf, I.; Gerhardt, L.M.; Tan, T.C.; Winter, C.; Holderried, T.A.; Chousterman, B.G.; Iwamoto, Y.; Liao, R.; Zirlik, A.; Scherer-Crosbie, M.; Hedrick, C.C.; et al. Ly-6Chigh monocytes depend on Nr4al to balance both inflammatory and reparative phases in the infarcted myocardium. Circ. Res. 2014, 114, 1611-1622.

57. Gordon, J.W.; Shaw, J.A.; Kirshenbaum, L.A. Multiple facets of NF- $\kappa B$ in the heart: To be or not to NF-кB. Circ. Res. 2011, 108, 1122-1132.

58. Burger, M.L.; Leung, K.K.; Bennett, M.J.; Winoto1, A. T cell-specific inhibition of multiple apoptotic pathways blocks negative selection and causes autoimmunity. eLife 2014, 3, e03468.

59. Harant, H.; Lindley, I.J. Negative cross-talk between the human orphan nuclear receptor Nur77/NAK-1/TR3 and nuclear factor-kappaB. Nucleic Acids Res. 2004, 32, 5280-5290.

60. Sekiya, T.; Kashiwagi, I.; Yoshida, R.; Fukaya, T.; Morita, R.; Kimura, A.; Ichinose, H.; Metzger, D.; Chambon, P.; Yoshimura, A. Nr4a receptors are essential for thymic regulatory T cell development and immune homeostasis. Nat. Immunol. 2013, 14, 230-237.

61. Sekiya, T.; Kashiwagi, I.; Inoue, N.; Morita, R.; Hori, S.; Waldmann, H.; Rudensky, A.Y.; Ichinose, H.; Metzger, D.; Chambon, P.; et al. The nuclear orphan receptor Nr4a2 induces Foxp3 and regulates differentiation of CD4+ T cells. Nat. Commun. 2011, doi:10.1038/ncomms1272.

62. Nowyhed, H.N.; Huynh, T.R.; Blatchley, A.; Wu, R.; Thomas, G.D.; Hedrick, C.C. The nuclear receptor Nr4a1 controls CD8 $\mathrm{T}$ cell development through transcriptional suppression of Runx3. Sci. Rep. 2015, doi:10.1038/srep09059.

63. Muto, G.; Kotani, H.; Kondo, T.; Morita, R.; Tsuruta, S.; Kobayashi, T.; Luche, H.; Fehling, H.J.; Walsh, M.; Choi, Y.; Yoshimura, A. TRAF6 is essential for maintenance of regulatory T cells that suppress Th2 type autoimmunity. PLoS ONE 2013, 8, e 74639.

64. You, B.; Jiang, Y.Y.; Chen, S.; Yan, G.; Sun, J. The orphan nuclear receptor Nur77 suppresses endothelial cell activation through induction of IkappaB alpha expression. Circ. Res. 2009, 104, $742-749$. 
65. Hamers, A.A.; Uleman, S.; van Tiel, C.M.; Kruijswijk, D.; van Stalborch, A.M.; Huveneers, S.; de Vries, C.J.; van't Veer, C. Limited role of nuclear receptor Nur77 in Escherichia coli-induced peritonitis. Infect. Immun. 2014, 82, 253-264.

66. Zhao, D.; Qin, L.; Bourbon, P.M.; James, L.; Dvorak, H.F.; Zeng, H. Orphan nuclear transcription factor TR3/Nur77 regulates microvessel permeability by targeting endothelial nitricoxide synthase and destabilizing endothelial junctions. Proc. Natl. Acad. Sci. USA 2011, 108, 12066-12071.

67. Zeng, H.; Qin, L.; Zhao, D.; Tan, X.; Manseau, E.J.; van Hoang, M.; Senger, D.R.; Brown, L.F.; Nagy, J.A.; Dvorak, H.F. Orphan nuclear receptor TR3/Nur77 regulates VEGF-A-induced angiogenesis through its transcriptional activity. J. Exp. Med. 2006, 203, 719-729.

68. Zhao, D.; Desai, S.; Zeng, H. VEGF stimulates PKD-mediated CREB-dependent orphan nuclear receptor Nurr1 expression: Role in VEGF-induced angiogenesis. Int. J. Cancer 2011, 128, 2602-2612.

69. McMorrow, J.P.; Crean, D.; Gogarty, M.; Smyth, A.; Connolly, M.; Cummins, E.; Veale, D.; Fearon, U.; Tak, P.P.; Fitzgerald, O.; et al. Tumor necrosis factor inhibition modulates thrombospondin-1 expression in human inflammatory joint disease through altered NR4A2 activity. Am. J. Pathol. 2013, 183, 1243-1257.

70. Kaipainen, A.; Kieran, M.W.; Huang, S.; Butterfield, C.; Bielenberg, D.; Mostoslavsky, G.; Mulligan, R.; Folkman, J.; Panigrahy, D. PPARalpha deficiency in inflammatory cells suppresses tumor growth. PLoS ONE 2007, 2, e260.

71. Huang, H.; Campbell, S.C.; Bedford, D.F.; Nelius, T.; Veliceasa, D.; Shroff, E.H.; Henkin, J.; Schneider, A.; Bouck, N.; Volpert, O.V. Peroxisome proliferator-activated receptor gamma ligands improve the antitumor efficacy of thrombospondin peptide ABT510. Mol. Cancer Res. 2004, 2, 541-550.

72. Palumbo-Zerr, K.; Zerr, P.; Distler, A.; Fliehr, J.; Mancuso, R.; Huang, J.; Mielenz, D.; Tomcik, M.; Fürnrohr, B.G.; Scholtysek, C.; et al. Orphan nuclear receptor NR4A1 regulates transforming growth factor- $\beta$ signaling and fibrosis. Nat. Med. 2015, 21, 150-158.

73. Niu, G.; Ye, T.; Qin, L.; Bourbon, P.M.; Chang, C.; Zhao, S.; Li, Y.; Zhou, L.; Cui, P.; Rabinovitz, I.; et al. Orphan nuclear receptor TR3/Nur77 improves wound healing by upregulating the expression of integrin $\beta 4$. FASEB J. 2015, 29, 131-140.

74. Lamouille, S.; Xu, J.; Derynck, R. Molecular mechanisms of epithelial-mesenchymal transition. Nat. Rev. Mol. Cell Biol. 2014, 15, 178-196.

75. Mix, K.S.; McMahon, K.; McMorrow, J.P.; Walkenhorst, D.E.; Smyth, A.M.; Petrella, B.L.; Gogarty, M.; Fearon, U.; Veale, D.; Attur, M.G.; et al. Orphan nuclear receptor NR4A2 induces synoviocyte proliferation, invasion, and matrix metalloproteinase 13 transcription. Arthritis Rheum. 2012, 64, 2126-2136.

76. Aherne, C.M.; McMorrow, J.; Kane, D.; FitzGerald, O.; Mix, K.S.; Murphy, E.P. Identification of NR4A2 as a transcriptional activator of IL-8 expression in human inflammatory arthritis. Mol. Immunol. 2009, 46, 3345-3357.

77. Okazaki, Y.; Sawada, T.; Nagatani, K.; Komagata, Y.; Inoue, T.; Muto, S.; Itai, A.; Yamamoto, K. Effect of nuclear factor-kappaB inhibition on rheumatoid fibroblast-like synoviocytes and collagen induced arthritis. J. Rheumatol. 2005, 32, 1440-1447. 
78. Maijenburg, M.W.; Gilissen, C.; Melief, S.M.; Kleijer, M.; Weijer, K.; Ten Brinke, A.; Roelofs, H.; van Tiel, C.M.; Veltman, J.A.; de Vries, C.J.; et al. Nuclear receptors Nur77 and Nurr1 modulate mesenchymal stromal cell migration. Stem Cells Dev. 2012, 21, 228-238.

79. Zhou, F.; Drabsch, Y.; Dekker, T.J.; de Vinuesa, A.G.; Li, Y.; Hawinkels, L.J.; Sheppard, K.A.; Goumans, M.J.; Luwor, R.B.; de Vries, C.J.; et al. Nuclear receptor NR4A1 promotes breast cancer invasion and metastasis by activating TGF- $\beta$ signalling. Nat. Commun. 2014, doi:10.1038/ncomms4388.

80. Kurakula, K.; Koenis, D.S.; van Tiel, C.M.; de Vries, C.J. NR4A nuclear receptors are orphans but not lonesome. Biochim Biophys Acta 2014, 1843, 2543-2555.

81. De Miranda, B.R.; Popichak, K.A.; Hammond, S.L.; Jorgensen, B.A.; Phillips, A.T.; Safe, S.; Tjalkens, R.B. The Nurr1 Activator 1,1-bis(3'-indolyl)-1-(p-chlorophenyl)methane Blocks Inflammatory Gene Expression in BV-2 Microglial Cells by Inhibiting NF-кB. Mol. Pharmacol. 2015, 87, 1021-1034.

(C) 2015 by the authors; licensee MDPI, Basel, Switzerland. This article is an open access article distributed under the terms and conditions of the Creative Commons Attribution license (http://creativecommons.org/licenses/by/4.0/). 